\title{
SÍTIO PLANALTO: UMA EXPERIÊNCIA EM CRIAÇÃO DE AVES CAIPIRAS
}

Apresentação: Relato de Experiência

\author{
Maciel Alves Tavares ${ }^{1}$; José Marques dos Santos ${ }^{2}$; Bruno Wallace do Carmo Perônico ${ }^{3}$; \\ Gizelia Barbosa Ferreira ${ }^{4}$; Mércia Cardoso da Costa Guimarães ${ }^{5}$
}

\section{Introdução}

Estima-se que as aves chegaram ao Brasil muito antes do descobrimento, através dos portugueses e/ou dos corsários. Assim, pode-se afirmar que a avicultura tem mais ou menos 500 anos de atividade em nosso país (SANTOS, 2009).

Atualmente, a produção brasileira de ovos totalizou 39,5 bilhões de unidades em 2016, superando em $6,1 \%$ a produtividade do ano interior. Esse aumento deve-se principalmente por ser o ovo um dos alimentos mais completos da dieta humana, apresentando uma composição rica em vitaminas, minerais, ácidos graxos e proteínas de excelente valor biológico (ALCÂNTARA, 2012).

Nosso país destaca-se ainda por ser o segundo maior exportador de carne de frango do planeta, essa posição é resultado da eficiência em manejo e da tecnologia genética das granjas (GOMES, 2017).

A criação de aves, seja no sistema industrial ou no caipira, tem garantido a segurança alimentar e nutricional e, elevado à renda dos agricultores familiares por todo Brasil. Nesse sentido, no dia 16 de setembro de 2017, durante o VI Congresso Latino-americano de Agroecologia, realizamos uma visita técnica ao Sítio Planalto, localizado na cidade de Brasília-DF, para conhecer o sistema de produção de galinhas caipiras orgânicas.

\section{. Relato de Experiência}

No dia 16 de setembro de 2017, durante o VI Congresso Latino-americano de Agroecologia, realizamos uma visita técnica ao Sítio Planalto, localizado na cidade de Brasília-DF, para conhecer o sistema de produção de galinhas caipiras orgânicas.

\footnotetext{
${ }^{1}$ Bacharelado em Agronomia, Instituto Federal de Pernambuco campus Vitória de Santo Antão, macieltavares15@gmail.com

${ }^{2}$ Bacharelado em Agronomia, Instituto Federal de Pernambuco campus Vitória de Santo Antão, josemarquesdossantos87@gmail.com

${ }^{3}$ Bacharelado em Agronomia, Instituto Federal de Pernambuco campus Vitória de Santo Antão, brunowperonico1@gmail.com

${ }^{4}$ Mestra em Agroecologia, Instituto Federal de Pernambuco campus Vitória de Santo Antão, gizelia.ferreira@vitoria.ifpe.edu.br

${ }_{5}$ Doutora em Engenharia Agrícola, Instituto Federal de Pernambuco campus Vitória de Santo Antão, mercia.guimaraes@vitoria.ifpe.edu.br
} 
Ao chegarmos à propriedade fomos guiados pelo Sr. Lucas, proprietário do Sítio Planalto, onde nos foi apresentado todo sistema de manejo e produção. Segundo Vieira (2012), a criação de galinhas caipiras orgânicas deve obedecer a alguns requisitos básicos, afinal, as aves estão sujeitas a problemas com a alimentação, sanidade e instalações, apesar de serem bastante rústicas.

As aves criadas na propriedade são mestiças de várias raças. A alimentação fornecida a esses animais é composta por farelo de milho crioulo misturado com folhas de moringa triturada e restos de hortaliças, tudo produzido no sítio, o que reduz bastante o custo de produção. Além da alimentação alternativa, outro fato que chamou a atenção foi à produtividade dos animais, uma vez que, as aves pesavam entre 4 e $6 \mathrm{~kg}$ de peso vivo e atingiam uma produtividade média de aproximadamente 260 ovos/ano. Todos esses fatores, aliados, fornecem uma renda mensal de aproximadamente $\mathrm{R} \$ 2.000,00$ reais a família.

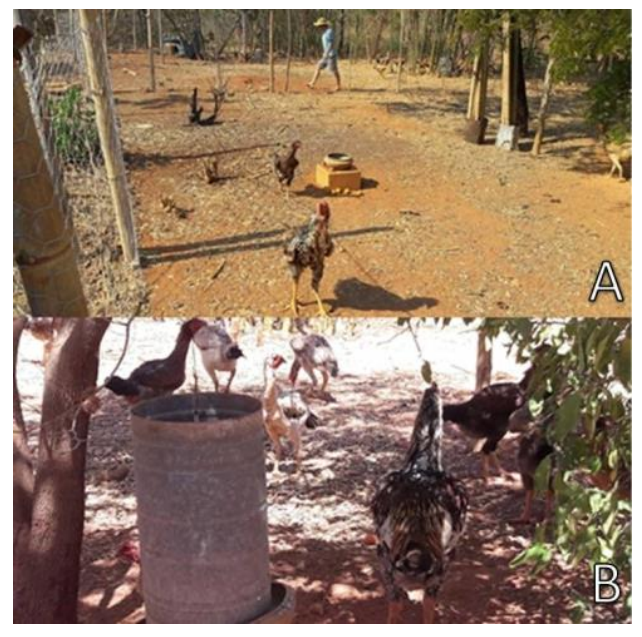

Figura 1. A - Local de pastejo das aves. B Aves. Fonte: Própria.

\section{Considerações}

Com a realização de visitas técnicas a esses espaços, podemos vivenciar e conhecer novos métodos de produção, que aliem produtividade à conservação do meio ambiente. Além disso temos a oportunidade de desenvolver saberes que venham contribuir para nossa formação profissional, visando o atendimento as exigências do mercado.

\section{Referências}

ALCÂNTARA, J.B. Qualidade físico-química de ovos comerciais: avaliação e manutenção de qualidade. Disponível em:

<http://ppgca.evz.ufg.br/up/67/o/SEMINARIO_2_juliana.pdf?1352294854> Acesso em: 06 jul. 2017.

GOMES, M. Produção de frango movimenta a economia do Brasil e do Distrito Federal. Disponível em:

<http://www.correiobraziliense.com.br/app/noticia/economia/2017/06/26/internas_economia,60482 5/producao-de-frango-movimenta-a-economia-do-brasil-e-do-distrito-federa.shtml> Acesso em: 13 Out. 2017.

VIEIRA, J. S .M. Criação de Galinhas Caipiras em Sistema Orgânico. Disponível em: <http://www.espacodoagricultor.rj.gov.br/pdf/criacoes/MANEJO_GALINHAS_CAIPIRAS_SISTE MAS_ORGANICOS.pdf> Acesso em: 13 Out. 2017.

SANTOS, M. W. Criação de Galinha Caipira pra produção de ovos em regime semiintensivo. Niterói: Rio Rural, 2009. 